\title{
SIGNIFICAÇÕES PARA O TRABALHO NA PÓS-MODERNIDADE
}

\author{
MEANINGS FOR THE WORK ON POST - MODERNITY
}

\author{
${ }^{1}$ Eduardo Torres Roberti \\ ${ }^{2}$ Ariel Salete de Moraes Júnior
}

\section{RESUMO}

O presente estudo tem por objeto as significações do trabalho na pós-modernidade. A sociedade pós-moderna é uma sociedade centrada na crise de identidade de indivíduo e na crise das ciências. É necessário demonstrar o impacto disso no trabalho. Concluindo que o trabalho é uma condição da existência do homem. Que na pós-modernidade é um meio de sobrevivência e exploração do homem distante do ideal de liberdade que relaciona o homem ao trabalho. No sentido de que a significação do trabalho na pós-modernidade é vazia da natureza real do trabalho, forma de exploração e de perseguição ao lucro e a riqueza.

Palavras-Chave: Trabalho. Pós-Modernidade. Crise do Sujeito. Significações do Trabalho. Natureza do Trabalho.
ABSTRACT
This study has, as its object, the meaning of labor in postmodernity. The postmodern society is a society centered on the individual's identity crisis and the crisis of science. It's necessary to demonstrate the impact of this in the labor field. Consider the labor as a condition of men existence, which, in the postmodernity, is a way of survival and exploration of the man, distant of the ideal of freedom that relates men to labor, in the sense that the meaning of labor in postmodernity is empty of the real nature of labor, exploration ways and persecution of profits and riches.
Keywords : Labor. Post-Modernity. Subject crisis. Significance of Labor. Nature of Labor.

\footnotetext{
${ }^{1}$ Mestrando em Direitos Humanos pela Universidade Tiradentes (UNIT), Aracaju, Sergipe, Brasil. Professor pela Universidade Tiradentes (UNIT), Aracaju, Sergipe, Brasil. Email: eduardo@ roberti.adv.br

${ }^{2}$ Doutorando pela Universidade Presbliteriana Mackenzie (SP), São Paulo, Brasil. Professor pela Universidade Tiradentes (UNIT), Aracaju, Sergipe, Brasil. Email: ariel.jr@uol.com.br
} 


\section{INTRODUÇÃO}

O presente estudo tem por objeto as significações do trabalho na pós-modernidade. Pautado pela ideia de que a sociedade pós-moderna é uma sociedade em crise, centrada na crise de identidade de indivíduo e na crise das ciências. É necessário demonstrar o impacto dessa visão no trabalho.

Ao passo que a modernidade oferece segurança e confiança, a pós-modernidade oferece perigos e riscos. Se questiona o impacto das evoluções do trabalho na qualidade de vida dos homens. Nesse sentido, imperioso apresentar a real natureza do trabalho enquanto processo que demonstra a relação do homem com a natureza até a sua coisificação, virando instrumento de si mesmo na produtividade capitalista.

Para ao final demonstrar as mutações da compreensão sobre o que vem a ser o trabalho ao longo da pós-modernidade, desde mero intercâmbio entre o homem e a natureza, passa a representar a compulsividade da dinâmica capitalista. Converte-se um fim em si mesmo, uma forma de auto e alta exploração e de perseguição ao lucro e a maximização da riqueza individual.

O objetivo do presente estudo é demonstrar as diversas significações do trabalho na pósmodernidade, sob o viés filosófico e crítico. Na pretensão de concluir que a atual sociedade de riscos, incertezas o indivíduo e as ciências em crise tornam uma significação do trabalho na pósmodernidade uma tarefa de construção complexa.

\section{A IMPORTÂNCIA DO TRABALHO}

Numa concepção apartada da visão marxista, o trabalho é instrumento de identidade e de libertação para o homem. Assim é considerado "o trabalho prestado em condições de dignidade valor indispensável para o processo de emancipação e de constituição da identidade social e coletiva do trabalhador" (DELGADO, 2012, p. 59). Sobre a identidade social desenvolvida especificamente por meio do trabalho:

[...] importa destacar que ela possibilita ao homem identificar-se intensamente como ser humano consciente e capaz de participar e de ser útil na dinâmica da vida em sociedade. Possibilita-lhe, também, desenvolver a consciência de que deve cuidar de si mesmo, preservando-se e exigindo que a dinâmica tutelada pelo Direito seja cumprida e aperfeiçoada para que esteja materialmente protegido (DELGADO, 2012, p. 59). 
Assume Edilton Meireles que é por intermédio do trabalho que não apenas se dá guarida à subsistência do trabalhador, mas também "por meio dele se desenvolve a própria personalidade da pessoa humana, em sua integralidade física e moral. É pelo trabalho que o homem se completa, se realiza, em toda a sua plenitude" (MEIRELES, 2012, p. 30).

O texto constitucional no Brasil é pródigo ao alinhavar o prestígio do trabalho, como no art. $1^{\circ}$, inciso IV, e caput do art. 170, firmando a valorização social do trabalho como um dos fundamentos da República Federativa, resguardando o homem-trabalhador nos aspectos objetivos e subjetivos. É nesse sentido, como assinalado por Marlton Murari, que o legislador constituinte deixou clara a intenção de proteger a figura humana do trabalhador, tanto em relação aos aspectos subjetivos, no que se refere à integridade física e mental, como no aspecto material, este considerado o trabalho como fonte de renda do trabalhador, e, agindo assim, empresta-lhe um mínimo de dignidade. Desse modo, a ordem econômica precisa ser compatibilizada com os fundamentos da República e com os direitos fundamentais (MURARI, 2008, p. 42).

Mesmo no sistema capitalista fixado no país, a ordem econômica precisa considerar as implicações da "valorização do trabalho humano" como fundamento da República, e, nessa direção, levar em conta a proteção à integridade do homem-trabalhador, na perspectiva do respeito à dignidade da pessoa humana.

A propósito, Noemia Porto observa que a flexibilização, no sentido de precarização, age como fator de desestabilização do valor "trabalho digno", consignando prevalência aí da autonomia privada. E, no caminho de refletir sobre o valor-trabalho, compreende que ele atua como mecanismo mais amplo para o exercício da cidadania (PORTO, 2013, p. 153-154)

Francis Fukuyama (2003, p. 53-57), com base em Hegel, refere-se ao fato de que, fundamentalmente, o progresso humano decorreu da busca de reconhecimento. A luta pelo reconhecimento agiu como fator propulsor do processo histórico a partir de uma "batalha cruenta" entre os dois competidores para revelar quem dominava e quem era dominado, mas, ao final, persistiu a democracia moderna, em que todos os cidadãos foram reconhecidos como livres e merecedores de igual reconhecimento. E essa circunstância, conforme Hegel, é central para o significado de ser humano. No entanto, diferentemente de Hegel, Francis Fukuyama admite um componente biológico, relacionado com o nível de serotonina no cérebro, a qual, como neurotramissora, assim como a dopamina e a noropinefrina, atuaria controlando o disparo de 
sinapses neurais e a transmissão de sinais, através dos neurônios no cérebro, afetando diretamente os sentimentos subjetivos de bem-estar, autoestima, medo e outros. Mas, ao fim, e no que interessa ao presente tópico sobre a importância do trabalho, assume que a busca pelo reconhecimento gerou praticamente todo o progresso humano, e que foi através de luta e trabalho que as pessoas puderam conquistá-lo. Acentua:

Durante praticamente toda a história humana, até o presente, a vida e a identidade das pessoas estiveram inseparavelmente ligadas à reprodução - isto é, ter família e criar filhos - ou à aquisição dos recursos para sustentar a si mesmas e às suas famílias. Família e trabalho enredam ambos os indivíduos numa teia de obrigações sociais sobre a qual eles frequentemente têm pouco controle e que são uma fonte de luta e ansiedade mas também de imensa satisfação. Aprender a cumprir essas obrigações sociais é uma fonte tanto de moralidade quanto de caráter (FUKUYAMA, 2003, p. 82)

O trabalho, enfim, é causa do desenvolvimento da identidade social do trabalhador, como também da própria personalidade da pessoa humana. Com isso, é albergado e impregnado pelo princípio da dignidade da pessoa humana. Como aspecto de valorização do trabalho humano inserido no texto constitucional, assume a condição de direito fundamental.

\section{OS DIREITOS FUNDAMENTAIS. UM CONCEITO.}

Para tratar dos direitos fundamentais, serve como ponto de partida o esclarecimento de Flávia Moreira Guimarães Pessoa de que “[...] conceituar o que sejam direitos fundamentais é uma tarefa particularmente difícil, tendo em vista a ampliação e transformação dos direitos fundamentais do homem no desenvolvimento histórico [...]” (PESSOA, 2009, p. 42), como também o fato de existirem várias denominações utilizadas, a exemplo de direitos naturais, direitos humanos e liberdades fundamentais.

Isso sugere mesmo que o conceito de direitos fundamentais oscila de acordo com o momento histórico. Essa circunstância já havia sido percebida por Ingo Wolfgang Sarlet, tanto que aponta a necessidade de retomada ou reconstrução histórica de um conceito (ideia aqui também considerada para os direitos fundamentais), ao observar que: 
[...] importa lembrar que também para a dignidade da pessoa humana aplica-se a noção referida por Bernard Edelman, de que qualquer conceito (inclusive jurídico) possui uma história, que necessita ser retomada e reconstruída, para que se possa rastrear a evolução da simples palavra para o conceito e assim apreender o seu sentido (SARLET, 2012, p. $33)$.

Várias são as vertentes e são muitas as teorias que cuidam e levam ao conceito e conteúdo dos direitos fundamentais. Numa delas, Arion Sayão Romita (2012, p. 51) define os direitos fundamentais como "os que, em dado momento histórico, fundados no reconhecimento da dignidade da pessoa humana, asseguram a cada homem as garantias de liberdade, igualdade, solidariedade, cidadania e justiça”.

Explicitando alguns elementos da definição como:

1) direitos fundamentais;

2) em dado momento histórico; e

3) fundados no reconhecimento da dignidade da pessoa humana, firma:

Direitos fundamentais são direitos. Direito é vocábulo genérico, que abrange os fundamentais e os demais. O termo direitos, empregado em sentido subjetivo, designa qualquer faculdade ou poder atribuído a uma pessoa pela ordem jurídica, que lhe assegura a possibilidade de reivindicá-lo quando desrespeitados. Em dado momento histórico. O reconhecimento dos direitos fundamentais depende da circunstância histórica, em cada lugar. Está superada a noção de direitos fundamentais centrada na natureza eterna e imutável do ser humano, considerada in abstrato, tal como preconizada pelo jusnaturalismo racional. Os direitos fundamentais dependem dos valores de cada sociedade, da cultura, do amadurecimento político, das crenças, do ambiente político (se autoritário ou democrático), daí sua historicidade. Fundados no reconhecimento da dignidade da pessoa humana, os direitos fundamentais repousam sobre o valor básico do reconhecimento da dignidade da pessoa humana (ROMITA, 2012, p. 51).

Um dos elementos mencionados - em dado momento histórico - por circunscrever os direitos fundamentais aos valores de cada sociedade, conforma-se com a percepção dos defensores do relativismo cultural, em descompasso com os adeptos do universalismo ou mesmo do 
multiculturalismo. Apesar disso, Arion Sayão Romita (2012, p. 81) em outra passagem afirma o caráter universal dos direitos fundamentais:

Em certo grau, impende reconhecer a ocorrência de variações culturais na aceitação dos direitos fundamentais por parte de diferentes Estados, porém não se pode afastar a ideia de que eles revestem caráter de universalidade, já que consagram valores inerentes à dignidade humana, válida em todos os quadrantes no universo, cujo respeito se impõe superiormente à margem de qualquer consideração contingente amparada em diversidades culturais.

Outra definição seria, como afirma Flávia Moreira Guimarães Pessoa (2009, p. 19), a de que os direitos fundamentais "são direitos subjetivos historicamente reconhecidos pelo Estado que visam a assegurar a dignidade da pessoas humana, quer pelo respeito às liberdades civis, quer pelo adimplemento dos direitos de natureza prestacional”, fazendo, com isso distinção entre os direitos fundamentais e os direitos humanos. Assinala que:

Observa-se, ainda, no conceito, que se trata de direitos reconhecidos pelo Estado, estabelecendo-se a distinção entre os direitos fundamentais, aqui compreendidos, e os direitos humanos de uma forma geral. O conceito assinala o objetivo maior dos direitos fundamentais, que é o respeito à dignidade da pessoa humana, cada vez mais reconhecido como o principal direito fundamental. Por fim, há a referência aos direitos fundamentais de defesa e de prestação, dois tipos básicos de direitos fundamentais.

Nessa linha, também Willis Santiago Guerra Filho (1997, p. 12) assinala que os direitos fundamentais são fixados através de normas jurídicas positivas, historicamente coincidindo com a proclamação dos direitos do homem, ao tempo em que faz a distinção entre direitos fundamentais e direitos do homem (direitos humanos). Enquanto os direitos fundamentais são aptos à produção de efeitos jurídicos, os direitos do homem apresentariam um conteúdo ético-político, com característica suprapositiva, a diferenciá-las das normas jurídicas internas.

Através das constituições, conforme Marlon Marcelo Murari, "todo o Direito passou a ser selado pelo signo da dignidade da pessoa humana, ou seja, todos os ramos de estudo do Direito passaram a ter um liame: o respeito aos direitos fundamentais", com a consequência de que "é a 
finalidade máxima de toda ordem jurídica, garantir as condições básicas que proporcionam ao cidadão o desenvolvimento integral da personalidade humana” (MURARI, 2008, p. 16).

Compreendidos no campo teórico e reconhecidos pelo Estado ao positivá-los, a “crise” dos direitos fundamentais é de efetivação.

Gabriela Neves Delgado e Maurício Godinho Delgado (2012, p. 60), a título de exemplificação, revelam que, para a consolidação da identidade social do trabalhador, é importante ocorrer a realização de práticas sociais, e, por isso, deve ser considerado que os direitos sociais agem como referência para acontecer a concretização dos demais direitos fundamentais.

\section{O TRABALHO NAS CONDIÇÕES PÓS-MODERNAS DA CRISE DE IDENTIDADE DO HOMEM}

Na modernidade líquida de Bauman (2003, p.96), “o trabalho adquiriu uma significação estética, espera-se que seja satisfatório em si e por si mesmo, raramente se espera que o trabalho faça os seres humanos melhores". A modernidade estaria concentrada no princípio do mercado e do Estado com ênfase ao debate do capitalismo com o socialismo, ensaiando uma lógica que aprisionaria ainda mais o homem nos grilhões do capitalismo. Na condição do trabalho, sua relação com o homem ficaria cada vez mais tomada por um distanciamento da real natureza do trabalho agora objetificado (REBOUÇAS, 2012).

O ente social pós-moderno, quando diante da atual complexidade da sociedade, dá-se conta de que "tudo que é sólido se desmancha no ar" (MARX e ENGELS, 2007, p. 15). É então que se instaura a mais profunda crise de identidade. Após uma longa jornada mergulhada nos mais diversos "ismos": teocentrismo, humanismo, individualismo, iluminismo, positivismo, marxismo, capitalismo e liberalismo, a humanidade encontra a necessidade de ruptura entre o presente e o passado, o que é formal e o informal, o algo concreto e o abstrato, o real e o imaginário - o indivíduo encontra-se com a modernidade. Esta é superada pelo surgimento de antigas e novas teorias, ideologias e pensamentos que travam tempo e espaço diante da complexidade da pós-modernidade.

Na abordagem de Hall (2006, p. 25), o ponto de partida e foco central de análise é a crise de identidade, na medida em que as antigas identidades, em ponto de desestabilidade, mergulham em declínio, e deste, instaura-se um amplo processo de mudanças onde surgem novas identidades fragmentadas e multifacetárias, e aquilo que refletia uma base sólida começa a se tornar uma 
referência que abala as estruturas da identidade do indivíduo. O referido autor parte de uma análise contextual das mudanças paradigmáticas como um todo para a reflexão destas alterações no processo de formação da identidade do próprio indivíduo.

Sendo assim, a concepção de Hall (2006, p. 26) para a identidade pós-moderna estabelece um indivíduo que não é estático, e sim dinâmico, não é simples, mas complexo, não mais oriunda da biologia do sujeito e sim de sua vivência histórica e cultural. O referido autor identifica a existência de uma crise de identidade e analisa qual o seu rumo, afirmando que a busca de uma identidade cultural se tornou um processo cada vez mais "provisório, variável e problemático" (HALL, 2006, p.12).

Não há como o indivíduo não se encontrar na mais profunda e complexa crise de identidade, uma vez que, é no contexto da modernidade tardia que, em meio às incertezas, o sujeito deve darse conta de que esta inserido numa mudança paradigmática maior e crucial a sua identidade, realidade inserida no paradigma emergente.

Sustentando que a sociedade se encontra em uma fase de transição, explica Santos (2006, p. 47) que o paradigma dominante diz respeito ao modelo de racionalidade herdado do Século XVI e consolidado no Século XIX, colocando-o como um modelo determinístico e cientificista, completamente totalitário. O autor, ao analisar a crise de identidade das ciências, propõe um modelo emergente, o qual denomina "paradigma de um conhecimento prudente para uma vida decente".

Diante do contexto do paradigma emergente de Santos (2006, p. 47), o indivíduo em crise de identidade trabalhado por Hall (2006, p. 28) verá que a fragmentação na ciência pós-moderna não é algo disciplinar, mas temático, como um emaranhado de galerias que se cruzam e entrecruzam.

Assim como na análise de Hall (2006, p. 29), onde, para encontrar uma solução para sua crise de identidade, o sujeito precisa dar-se conta de que está inserido num contexto de tradição e cultura que forma uma identidade cultural, e também na análise da transição de paradigmas de Santos (2006, p. 48), onde o indivíduo precisa regressar as raízes e dar-se conta de que produzir conhecimento não se separa de seus produtos. Vislumbra-se, portanto, a dinâmica da análise sobre as crises da modernidade tardia. Nesse sentido, é possível identificar que a mola propulsora da 
sociedade contemporânea são as crises. Esse é o "elemento específico e peculiar” das mudanças na modernidade tardia como citou Hall (2006, p.24), inerente ao dinamismo do atual contexto social da globalização.

Por fim, quando abordamos as crises na modernidade tardia, seja a crise de identidade do indivíduo em Hall (2006, p. 24) ou a crise de identidade das ciências em Sousa Santos, estamos falando de uma sociedade em crise. Se ao indivíduo faltam referências sólidas, se às ciências faltam referências de aproximação científica e se a linguagem é tida como limitadora da superação da relação sujeito-objeto, se esta falando de uma sociedade em crise. Sobretudo, tema recorrente das atuais reflexões acadêmicas, a crise está instaurada e vivem-se crises de identidade a todo o momento, sem ao menos perceber que o fim pode ser a perda da identidade, e que a solução talvez seja interagir através do método dialético e dialógico proposto pela espiral circular de compreensão, tendo na linguagem a condição de possibilidade de compreensão e interpretação desta sociedade complexa, repleta de incertezas, antagonismos, contradições e paradoxos, inserida num contexto de transição de paradigmas, peculiar da pós-modernidade ou modernidade tardia.

O mundo do trabalho, nessa perspectiva, tem sofrido profundas alterações oriundas da apropriação privada do trabalho social. As relações de trabalho na atual conjuntura têm algumas características principais, tais como: a perda da importância do trabalho individual, a partir de um processo de integração da capacidade social do trabalho, o que aumenta os níveis de produtividade, atendendo o objetivo principal da acumulação capitalista, qual seja, o lucro, e dissolvendo as possibilidades de articulação da classe trabalhadora cada vez mais fragmentada pelo processo de mundialização econômica; profundo deslocamento de trabalho vivo para trabalho morto o que otimiza os processos produtivos, diminuindo os custos, contribuindo para a conservação, manutenção e ampliação da acumulação de riquezas; alteração da proporção nas mudanças desempenhadas pela força de trabalho no processo de valorização do capital, tendo na flexibilização e na polivalência do trabalhador assalariado os exemplos dessa realidade, implicando na expressiva redução dos postos de emprego, levando ao achatamento dos salários e ampliação do contingente de reserva; acelerada inovação tecnológica, potencializada pelo desenvolvimento das forças produtivas na apropriação do trabalho intelectual.

A pós-modernidade é um movimento de ruptura que surgiu nos fins do Século XX, onde o conceito de progresso moderno vai sendo substituído pelo de crise e de incredulidade. Inúmeras 
transformações ocorrem em relação à concepção que se tem sobre o trabalho. A ideia essencial deste primeiro tópico do trabalho foi apresentar as concepções sobre a pós-modernidade sob as perspectivas da crise - de identidade e das ciências - para então, a partir do tópico seguinte, compreender o trabalho sob a perspectiva de sua natureza.

\section{A REAL NATUREZA DO TRABALHO}

O trabalho é uma forma exclusivamente humana. Uma premissa que se aproxima de uma premissa maior - onde existem indivíduos existe uma sociedade - e o trabalho é significativo para a realização do homem enquanto ser social. Afirma Engels (1876 apud ANTUNES, 2001, p. 16) que o trabalho é o que distingue os seres humanos dos outros animais.

O trabalho aufere transformações no homem, uma vez que este atua sobre a natureza, dominando-a e transformando-a no exercício do seu poder (LUKACS, 2012, p. 87). Trabalhar implica em intervenções do homem sobre a natureza, esta fornecendo os meios e objetos necessários para o processo de transformação que o homem, com sua capacidade de trabalhar, realizará.

É assim o trabalho um processo que produz todos os elementos necessários para que a sobrevivência seja auferida e que a existência passe a ter sentido. É um verdadeiro e virtuoso processo. (MARX, 2005, p. 34).

Os recursos são escassos e as necessidades humanas são ilimitadas. Esse é o paradoxo econômico contemporâneo, em verdade o sempre foi para a sociedade. O trabalho é ligado a atender as necessidades humanas, sendo útil na realização de produtos que geram riqueza, sendo o trabalho uma forma de produção de riqueza (PRIEB e CARCANHOLO, 2011, p. 112).

Na forma social atual - de capitalismo e consumismo - os meios de produção são embrionários de uma propriedade privada e a sociedade passa a ser dividida em classes distintas e interligadas linearmente: os proprietários - aqueles que produzem mercadorias e suprem as lacunas e necessidades sociais e os trabalhadores - que nada possuem além da necessária venda de sua capacidade de trabalho. Estas duas classes travam entre si uma relação de hipossuficiência, em que o trabalhador é o elo mais fraco da relação.

O trabalho é dispêndio de força humana de trabalho e nessa quantidade de trabalho humano cria o valor das mercadorias, e sob uma forma especial, para um determinado fim, e, nessa 
quantidade de trabalho útil e concreto, produz valores de uso. Mercadorias são a forma elementar da riqueza capitalista. Seu valor é medido pelo trabalho nela empregado.

O detentor do trabalho - o trabalhador - é um sujeito de direitos que dispõe de sua força de trabalho como uma verdadeira mercadoria, e cuja sua exploração é feita por intermédio de uma relação linear e desigual, que é a relação de trabalho, subscrita por uma forma jurídica que o torna hipossuficiente - o contrato de trabalho. Nesse sentido, o próprio trabalho humano é mercadoria em circulação no mercado onde o trabalho é consumido na produção de riqueza. (PACHUKANIS, 1989, p. 122).

No sistema capitalista, o trabalhador é um meio de valorização do capital, uma vez que não produz para si, mas para o próprio capital. Ao mesmo tempo é o trabalho a fonte de valor que representa para Marx (2011, p. 32) uma possibilidade universal de riqueza - uma atividade. Em verdade uma contradição absoluta ao capital. Nesta atividade, o homem proprietário de seu trabalho aliena ao capital sua fonte criadora de riqueza e passa ser incorporado pela produção, tendo então um contrato jurídico de trabalho que serve como garantia de exploração capitalista do trabalho. (DUSSEL, 1995, p. 34).

O trabalho passa a ser condição para o consumo. Como consequência, tem-se a perda do sentido do trabalho, enquanto motor da ação humana, para fins de desenvolvimento e aprendizagem de novos conhecimentos e habilidades. Ele fica subjulgado a uma nova esfera de produção: não de mercadorias, mas sim de bens de consumo. Como bem afirma Bauman (2008, p.185), “o valor e o glamour do trabalho se medem hoje com parâmetros estabelecidos para a experiência do consumidor".

O trabalho é também, como registrado em outro tópico, noutra concepção, apartada da visão marxista, instrumento de identidade e de libertação para o homem. Assim, é considerado "o trabalho prestado em condições de dignidade valor indispensável para o processo de emancipação e de constituição da identidade social e coletiva do trabalhador" (DELGADO, 2012, p. 59). Sobre a identidade social desenvolvida especificamente por meio do trabalho, importa destacar que ela possibilita ao homem identificar-se intensamente como ser humano consciente e capaz de participar e de ser útil na dinâmica da vida em sociedade. Possibilita-lhe, também, desenvolver a consciência de que deve cuidar de si mesmo, preservando-se e exigindo que a dinâmica tutelada pelo Direito seja cumprida e aperfeiçoada para que esteja materialmente protegido (DELGADO, 2012, p. 59). 
É que, como adianta Edilton Meireles (2012, p. 30), por intermédio do trabalho que não apenas se dá guarida à subsistência do trabalhador, mas também “por meio dele se desenvolve a própria personalidade da pessoas humana, em sua integralidade física e moral. É pelo trabalho que o homem se completa, se realiza, em toda a sua plenitude".

Consubstancia esse fato o ramo jurídico do Direito Trabalhista que emerge na modernidade para regular as relações de trabalho, nos moldes do contrato de trabalho, e que ao mesmo tempo em que protege a classe trabalhadora de uma exploração desenfreada, organiza esta exploração detalhadamente assim, contribuindo para justificá-la. Como já visto anteriormente, o indivíduo e as ciências em crise tornam uma significação do trabalho na pós-modernidade uma tarefa de construção complexa.

Nunca é demais lembrar que "a origem primeira do direito do trabalho remete à realidade de exploração vivenciada, ao final do século XVIII, pelos trabalhadores da Europa Ocidental, que deu margem a uma série de conflitos e insurreições”. (PESSOA, 2009, p. 16).

Neste segundo tópico do desenvolvimento deste trabalho, buscou-se demonstrar a real natureza do trabalho numa breve construção teórica em que se define ser a natureza do trabalho a própria natureza humana, uma condição da existência do homem.

\section{AS METAMORFOSES DO TRABALHO E SUAS SIGNIFICAÇÕES NA PÓS- MODERNIDADE}

Compreender o trabalho como processo ou atividade elementar do homem é indispensável para a sua realização como seres sociais, estes que sofrem variações em razão do período histórico em que aparecem na sociedade da qual fazem parte. Em seu primeiro momento o homem realizava apenas o esforço de complementar a natureza com a extração daquilo que dela se apresentava uma economia de subsistência direta em que o homem era dependente da natureza. Com as primeiras civilizações deixando a vida isolada, constituindo sociedades mais complexas, se desenvolveu a agricultura, as noções de propriedade e excedente de produção. (ANTUNES, 2006, p. 67).

A concepção de que o homem se eleva como ser humano em razão do trabalho é moderna, completamente alheia às concepções filosóficas gregas, romanas e cristãs sobre o trabalho. Na antiguidade romana e grega, a virtude da vida humana era atrelada à noção de ócio. O tempo livre 
para desfrutar da vida ou dedicar-se a política era a melhor condição de vida humana. $O$ trabalhador era um escravo - membro socialmente inferior da sociedade ou nem mesmo pertencente a ela e, até por vezes, coisa pertencendo a alguém. (ANTUNES, 2006, p. 84).

Na concepção cristã o trabalho era concebido como uma pena na qual o homem estava condenado pelo pecado. Como descrito no Antigo Testamento, por terem perdido a sua inocência das origens no paraíso, Adão teria sido condenado a ganhar o seu pão com o suor de seu rosto e Eva às dores do "trabalho" do parto.

A modernidade rompeu a cultura medieval enraizada na antiguidade e concebida pelo cristianismo sobre o trabalho como algo indigno. Com a Reforma Protestante, o trabalho ganhou um novo significado, passou a representar a base da vida - sendo o ócio uma evasão antinatural e perniciosa. Ao manter-se por seu trabalho o homem estava servindo ao seu Deus. Assim, o trabalho passou a ser a vocação do homem, mais do que uma obrigação, uma virtude.

O trabalho passou a ser um meio de interação entre o homem e sua atividade criadora, e, longe de escravizar o homem ou puni-lo, passou a ser uma real condição necessária para a emancipação do homem. Com a cristalização dos lemas da Revolução Francesa - igualdade, liberdade e fraternidade - o trabalho afirmou-se como algo vindo de homens iguais, uma atividade livremente prestada por homens livres. (ANTUNES, 2006, p. 86).

Com a ascensão da classe burguesa ao poder social e político surgiram às figuras daqueles que exerceriam a propriedade dos meios de produção e a relação de emprego, na qual o trabalhador que dispõe de seu trabalho o vincula a um contrato de trabalho e se torna subjetivo do seu objetivo poder de trabalhador. (ANTUNES, 2006, p. 102).

Com a globalização corporificada e o sistema capitalista o trabalho passa a ser degradado, convertendo-se em meio necessário para a subsistência, e negociável como mercadoria. O homem - trabalhador - passa a ser um simples meio para que o outro homem - proprietário - gere sua riqueza. (ANTUNES, 2006, p. 104).

No Século XX, a separação entre aqueles que executam e aqueles que planejam o trabalho consolidou um novo paradigma em que a fragmentação e a especialização das tarefas de produção seriam a tônica do trabalho. Aqui se verifica a separação total entre aquele que produz e o seu produto. É o que a doutrina compreende como alienação do trabalho. O trabalhador é alienado ao 
trabalho e ao produto, uma vez que é a soma da fragmentação do processo de produção que se torna no produto e não o trabalhador o faz trabalho. E essa realidade se vê em larga escala, massificada, onde o trabalhador é contratado com vistas à prestação de um trabalho em si mesmo, e não em relação ao seu produto final.

Na pós-modernidade, o trabalho de mero intercâmbio entre o homem e a natureza passa a representar a compulsividade da dinâmica capitalista. Converte-se um fim em si mesmo, uma forma de auto e alta exploração e de perseguição ao lucro e a maximização da riqueza individual.

É o trabalho flexível, fenômeno que tem sido trazido e estudado na contemporaneidade e traz como características principais a redução do emprego, a ampliação da terceirização, trabalho informal, home-work e as exigências por múltiplas funções, que desqualificam e assujeitam o trabalhador. Dessa forma, a flexibilidade torna-se um dos pilares da sociedade líquida moderna, sendo uma das características necessárias aos indivíduos para sobreviverem à instabilidade do tempo presente. Quando observada no campo do trabalho "[...] ela anuncia empregos sem segurança, compromissos ou direitos que oferecem apenas contratos a prazo fixo ou renováveis, demissão sem aviso prévio e nenhum direito à compensação [...]” (BAUMAN, 2001, p.185). Amplia-se a sensação de descartabilidade e a necessidade de construir meios para competir com o outro, em vista de uma realidade social no qual os postos de trabalho tornam-se cada vez mais escassos.

O trabalho é a uma atividade de autotransformação do homem - um meio de vida. O trabalho então assume o caráter de liberdade reconquistada para o ser que vence a natureza. Livre é aquele que exerce o trabalho ou o trabalho é o que dignifica o homem. Nesse cenário, Beck (2003, p. 98) ressalta que, quanto mais as relações, as condições e o mercado de trabalho são "desregulamentados" e "flexibilizados", mais rapidamente e com mais eficiência a sociedade do trabalho se transforma em sociedade de risco. Tecendo duras críticas ao capitalismo, Beck (2003, p. 99) entende o momento atual do mundo do trabalho como um momento de incerteza.

Mas como se viu no primeiro capítulo, o homem é um ser em crise num ambiente de transformações, incertezas, caótico, onde o ente social que constata o sólido desmanchando-se no ar, é capaz de identificar que, diante de sua complexa crise de identidade, ante o contexto do paradigma emergente, a sociedade deve ser compreendida numa lógica de articulação entre desordem, ordem e organização, onde o movimento circular de compreensão desta sociedade é 
aberto e fechado, simples e complexo, onde é impossível pensar a ordem da desordem, o estático sem o dinâmico, o todo sem as partes.

Em sendo o trabalho a própria natureza humana, uma condição da existência do homem, que na pós-modernidade é garantida como um meio de sobrevivência e exploração do próprio homem, torna-se distante o ideal de liberdade que relaciona o homem e o trabalho, no sentido de que a significação do trabalho na pós-modernidade é vazia da natureza real do trabalho, tornadose apenas um instrumento de subjetividade do indivíduo, mera forma de exploração e de perseguição ao lucro e a riqueza.

\section{CONSIDERAÇÕES FINAIS}

O presente estudo teve por objeto as significações do trabalho na pós-modernidade. Viu-se no primeiro capítulo que o homem é um ser em crise num ambiente de transformações, incertezas, caótico, onde o ente social que constata o sólido desmanchando-se no ar, é capaz de identificar que, diante de sua complexa crise de identidade, ante o contexto do paradigma emergente, a sociedade deve ser compreendida numa lógica de articulação entre desordem, ordem e organização, onde o movimento circular de compreensão desta sociedade é aberto e fechado, simples e complexo, onde é impossível pensar a ordem da desordem, o estático sem o dinâmico, o todo sem as partes.

Ao final demonstrou-se que as mutações da compreensão sobre o que vem a ser o trabalho ao longo da pós-modernidade, desde mero intercâmbio entre o homem e a natureza, passa a representar a compulsividade da dinâmica capitalista. Converte-se um fim em si mesmo, uma forma de auto e alta exploração e de perseguição ao lucro e a maximização da riqueza individual.

O objetivo do presente estudo foi demonstrar as diversas significações do trabalho na pósmodernidade, sob o viés filosófico e crítico. Concluindo que o trabalho é a própria natureza humana, uma condição da existência do homem, que na pós-modernidade é garantida como um meio de sobrevivência e exploração do próprio homem, torna-se distante o ideal de liberdade que relaciona o homem e o trabalho, no sentido de que a significação do trabalho na pós-modernidade é vazia da natureza real do trabalho, tornado-se apenas um instrumento de subjetividade do indivíduo mera forma de exploração e de perseguição ao lucro e a riqueza. 


\section{REFERÊNCIAS}

ANTUNES, Ricardo. Adeus ao Trabalho: Ensaios sobre as metamorfoses e a centralidade do mundo do trabalho. $11^{\text {a }}$ Edição. Editora Cortez, 2006

Os sentidos do trabalho - ensaios sobre a afirmação e a negação do trabalho. São

Paulo: Boitempo, 2001.

BAUMAN, Zygmunt. A Sociedade Individualizada: vidas contadas e histórias vividas. Rio de Janeiro: Zahar, 2008.

Modernidade líquida. Rio de Janeiro: Zahar, 2001, Cap. 4.

BECK, Ulrich. A reinvenção da política: rumo a uma teoria da modernização reflexiva. Modernização Reflexiva. São Paulo: Unesp, 1995.

. Liberdade ou Capitalismo. Tradução Luiz Antônio Oliveira de Araújo. São Paulo:

UNESP, 2003.

DELGADO, Gabriela Neves; DELGADO, Maurício Godinho. Constituição da República e direitos fundamentais. São Paulo: LTr, 2012.

DUSSEL, Enrique. Filosofia da Libertação: crítica à ideologia da exclusão. São Paulo: Paulus Editora, 1995.

ENGELS, Friedrich. Sobre o papel do Trabalho na Transformação do Macaco em Homem. Edição de Ridendo Castigat Mores, 1876. Edição Eletrônica: Ed. Ridendo Castigat Mores (www.jahr.org) acesso em junho de 2016.

FUKUYAMA, Francis. Nosso futuro pós-humano. Rio de Janeiro: Rocco, 2003.

GUERRA FILHO, Willis Santiago. Direitos fundamentais, processo e princípio da proporcionalidade. In: GUERRA FILHO, Willis Santiago (coord.). Dos direitos humanos aos direitos fundamentais. Porta Alegre: Livraria do Advogado, 1997.

HALL, Stuart. A Identidade Cultural na Pós-Modernidade. $11^{\text {a }}$ ed. Rio de Janeiro: DP\&A, 2006. 
LUKACS, Gyorgy. Para uma ontologia do ser social I. São Paulo: Boitempo, 2012.

MARX, Karl. Crítica da filosofia do direito de Hegel. São Paulo: Boitempo, 2005. . Grundrisse: manuscritos econômicos de 1857-1858. São Paulo: Boitempo, 2011. ; ENGELS, Friedrich. A ideologia alemã. Rio de Janeiro: Civilização Brasileira, 2007.MEIRELES, Edilton. A constituição do trabalho. 1 ed., São Paulo: Ltr, 2012.

MURARI, Marlon Marcelo. Limites constitucionais ao poder de direção do empregador e os direitos fundamentais do empregado. São Paulo: Ltr, 2008.

PACHUKANIS, Yevgeny Bronislavovich. A teoria geral do direito e o marxismo. Rio de Janeiro: Renovar, 1989.

PESSOA, Flávia Moreira Guimarães. Relações de Trabalho na Sociedade Contemporânea. São Paulo: LTr.2009.

Juspodivm, 2009. Curso de direito constitucional do trabalho. Salvador:

PRIEB, Sérgio A. M.; CARCANHOLO, Reinaldo. O trabalho em Marx. Em: CARCANHOLO, Reinaldo (org.). Capital: essência e aparência. Vol. 1. São Paulo: Expressão Popular, 2011.

PORTO, Noemia. O trabalho como categoria constitucional de inclusão. São Paulo: Ltr, 2013. REBOUÇAS, Gabriela Maia. Tramas entre subjetividades e direito: a constituição do sujeito em Michel Foucault e os sistemas de resolução do conflitos. Rio de Janeiro: Lumen Juris, 2012.

ROMITA, Arion Sayão. Direitos fundamentais nas relações de trabalho. São Paulo: Ltr, 2012. SANTOS, Boaventura de Sousa. Um discurso sobre as ciências. $4^{\text {a }}$ ed. São Paulo: Cortez, 2006. SARLET, Ingo Wolfgang. Dignidade da pessoa humana e direitos fundamentais. 2. ed. Porto Alegre: Livraria do advogado, 2012. 